\title{
Increased Energy Expenditure in Gastric Bypass Rats Is Not Caused by Activated Brown Adipose Tissue
}

\author{
Mohammed Hankir $\# a, b \quad$ Marco Bueter ${ }^{\# a, c} \quad$ Willy Gsell ${ }^{d} \quad$ Florian Seyfried $^{a}$ \\ Magdy Khalild Kirsty L. Smith ${ }^{a} \quad$ Steve R. Bloom ${ }^{a} \quad$ Jimmy D. Bell ${ }^{b}$ Carel W. le Roux ${ }^{a}$ e \\ amperial Weight Centre, Department of Investigative Medicine, Imperial College London, \\ Hammersmith Hospital, ${ }^{b}$ Metabolic and Molecular Imaging Group, Medical Research Council Clinical \\ Sciences Centre, London, UK, 'Department of Surgery, University of Zurich, Zurich, Switzerland, \\ ${ }^{\mathrm{d} B i o l o g i c a l}$ Imaging Centre, Medical Research Council, Clinical Sciences Centre, Imperial College \\ London, Hammersmith Hospital, London, UK, experimental Pathology, Conway Institute, School of \\ Medicine and Medical Sciences, University College Dublin, Ireland
}

\# Mohammed Hankir and Marco Bueter have contributed equally to this paper.

\section{Key Words}

Gastric bypass $\cdot$ Brown adipose tissue $\cdot$ Positron emission tomography / computed tomography $\cdot$ Uncoupling protein- $1 \cdot$ Energy expenditure

\begin{abstract}
Objective: To investigate whether gastric bypass induces a higher activity of brown adipose tissue and greater levels of the brown adipose tissue-specific protein uncoupling protein-1 (UCP-1) in rats. Methods: Gastric bypass rats and sham-operated controls (each $n=8$ ) underwent whole body ${ }^{1} \mathrm{H}$-MR spectroscopy for analysis of body composition and ${ }^{18} \mathrm{~F}$-fluorodeoxyglucose positron emission tomography combined with computed tomography ( ${ }^{18} \mathrm{~F}-\mathrm{FDG} \mathrm{PET} /$ $\mathrm{CT}$ ) imaging for measurement of the metabolic activity of brown adipose tissue. Brown adipose tissue was harvested and weighed, and UCP-1 mRNA content was measured by Northern Blot technique. Results: Gastric bypass rats had a significantly lower percentage of whole body adipose tissue mass compared to sham-operated rats $(p=0.001)$. There was no difference in brown adipose tissue activity between the two groups (standardised uptake value sham $2.81 \pm 0.58$ vs. bypass $2.56 \pm 0.46 ; p=0.73$ ). Furthermore, there was no difference in the UCP-1 mRNA content of brown adipose tissue between the two groups (sham $49.5 \pm 13.2$ vs. bypass $43.7 \pm 13.1 ; p=0.77$ ). Conclusion: Gastric bypass does not increase the activity of brown adipose tissue in rats suggesting that other mechanisms are involved to explain the increased energy expenditure after bypass surgery. Our results cannot justify the radiation dose of ${ }^{18} \mathrm{~F}$-FDG PET/CT studies in humans to determine potential changes in brown adipose tissue after gastric bypass surgery.




\section{Introduction}

The prevalence of obesity has markedly increased world-wide in the last decade and is associated with increased morbidity and mortality [1]. The personal, social and economic consequences of this global obesity epidemic are comprehensive [2,3]. Obesity surgery is currently the most effective therapy for morbid obesity, achieving significant and sustained weight loss with a proven mortality benefit $[4,5]$. Increasing numbers of surgical procedures such as the Roux-en-Y gastric bypass (gastric bypass) are being performed worldwide [6], but the mechanisms underlying the superiority in inducing and maintaining body weight loss remains a matter of controversy and active investigation. Initially, it was widely assumed that weight loss after gastric bypass was simply due to mechanical restriction and caloric malabsorption alone [7]. However, recent studies have indicated that there are more complex mechanisms by which gastric bypass decreases caloric intake, such as reduced hunger $[8,9]$, increased satiety $[8,9]$, altered taste $[10,11]$ as well as reduced preference for foods with a high fat and sugar content [12]. In addition, we and others have investigated the changes in energy expenditure following gastric bypass, demonstrating that gastric bypass surgery in rats not only prevented the expected decrease in energy expenditure subsequent to body weight loss but actually increased energy expenditure [13,14], and this was not accounted for by increased physical activity [13]. It was shown that maintenance as well as diet-induced thermogenesis was higher after gastric bypass surgery compared to body weight-matched controls [13].

Anecdotally, patients after gastric bypass appear to be more tolerant to exposure to cold temperatures than those with gastric banding, and thus the question arises whether gastric bypass may enhance cold-induced thermogenesis. Brown adipose tissue is the principle thermogenic organ in rodents that mediates both cold-induced and diet-induced thermogenesis [15]. Traditionally in humans brown adipose tissue was thought only to be present in neonates [16]. However, the presence of functional brown adipose tissue in adult humans has recently been demonstrated through the use of positron emission tomography combined with computed tomography (PET/CT) and biopsy studies [17-19]. The important role brown adipose tissue plays in promoting a negative energy balance is supported by the observation that ablation and expansion of brown adipose tissue in mice results in obesity and resistance to diet-induced obesity respectively $[15,20]$. Moreover, brown adipose tissue activity is negatively correlated with BMI in humans [17].

Thermogenic activity is dependent on the volume of brown adipose tissue, the uncoupling protein-1 (UCP-1) content and the degree of stimulation by the sympathetic nervous system [21]. UCP-1 is a 32-kDa protein located in the inner mitochondrial membrane and is expressed uniquely in brown adipose tissue [22]. UCP-1 is necessary for both diet-induced and temperature-induced thermogenesis in mice $[23,24]$ and has also been reported to play important roles for energy homeostasis in rodents and neonates of larger mammals including humans [22].

The aim of our study was to assess whether gastric bypass in rats would induce a higher activity of brown adipose tissue using the PET-sensitive metabolic tracer ${ }^{18} \mathrm{~F}$-fluorodeoxyglucose $\left({ }^{18} \mathrm{~F}-\mathrm{FDG}\right)$ and also to measure UCP-1 levels from brown adipose tissue extracts. Based on the outcome of this study, we would then be in a position to make an informed decision as to whether similar human studies would be scientifically and ethically justified. 
Hankir et al.: Increased Energy Expenditure in Gastric Bypass Rats Is Not Caused by Activated Brown Adipose Tissue

\section{Material and Methods}

Animals

Obese male Wistar rats were randomised to a gastric bypass operation $(n=8)$ or sham operation ( $\mathrm{n}=8$ ). Rats were individually housed under a 12-hour / 12-hour light-dark cycle and at a room temperature of $21 \pm 2 \stackrel{\circ}{\circ}$. Water and standard chow were available ad libitum. Body weight and food intake were measured daily. All experiments were performed under the British Home Office Animals (Scientific Procedures) Act 1986 (PPL 70/6669).

\section{Surgery}

Surgery was performed according to an established protocol [25]. Briefly, the proximal jejunum was divided $15 \mathrm{~cm}$ distal to the pylorus to create a biliopancreatic limb. After identification of the caecum, the ileum was then followed proximally to create a common channel of $25 \mathrm{~cm}$. Here, a $7 \mathrm{~mm}$ side-to-side jejunojejunostomy between the biliopancreatic limb and the common channel was performed. The gastric pouch and alimentary limb was anastomosed end-to side, and the gastric remnant was closed. Sham operations consisted of a 7-mm gastrotomy on the anterior wall of the stomach with subsequent closure and a 7-mm jejunotomy with subsequent closure.

\section{Body Composition Analysis Using Whole Body ${ }^{1} H$-MR Spectroscopy}

Whole body ${ }^{1} \mathrm{H}-\mathrm{MR}$ spectroscopy for analysis of body composition was carried out on post-operative day 45 as previously described [26]. Briefly, animals were anaesthetised and scanned on a 4.7T Unity Inova MR Scanner (Varian. Inc., Palo Alto, CA, USA). Temperature and respiration was monitored throughout the scan using monitoring equipment (SA Instruments, Inc., Stony Brook, NY, USA), and animals were maintained at room temperature. ${ }^{1} \mathrm{H}$-MR spectroscopy was performed using a single pulse sequence with a repetition time (TR) of $10 \mathrm{~s}$, a pulse angle of $45^{\circ}$, four averages and a spectral width of 20,000 Hz. The spectra were analysed using MestRe-C (Mestrelab Research, Santiago de Compostela, Spain).

\section{${ }^{18}$ F-FDG-PET/CT Imaging}

Studies were performed on post-operative day 40 with a combined PET/CT preclinical scanner (Inveon, Siemens Medical Solutions, Erlangen, Germany). This system has been evaluated and physically characterised in the literature to produce PET images of high spatial resolution (1.5 mm FWHM at the centre) [27]. The scanner has an axial length of $127 \mathrm{~mm}$ and a crystal ring diameter of $161 \mathrm{~mm}$. The CT component of the scanner provides anatomical localisation in addition to correction for photon attenuation. After an overnight fast, all rats were anaesthetised with a 2-4\% isofluorane-oxygen mix maintained throughout the scan via a face-mask. Temperature and respiration was measured throughout the scan using BioVet software (BioVet Rev 03, m2m Imaging Corp., Cleveland, OH, USA), and animals were maintained at room temperature. They received an intravenous tail vein catheterisation followed by i.p. administration of the $\beta-3$ adrenergic receptor agonist CL316, $243(1 \mathrm{mg} / \mathrm{kg}$, Sigma Aldrich, Gillingham, UK) half an hour before PET/CT scans. For the scans the Inveon acquisition workplace was used which provides a workflow mechanism where acquisitions required can be batched in one imaging session with minimal user intervention. A 3 bed-position CT scan was acquired for each animal study where the interscapular region was ensured to be in the centre of the imaging field of view. CT scanning was performed with a current of $500 \mu \mathrm{A}$ and tube voltage of $80 \mathrm{kVp}(\mathrm{kVp}=$ peak kilovoltage) using 220 projections and an exposure time of $200 \mathrm{~ms}$. An overlap of $20 \%$ was used between the sequential CT bed positions. For the PET scan following the CT scan, the animal bed was shifted to the PET ring of the machine where injection and data acquisition was accomplished. A 1-hour list mode data acquisition was used in all studies simultaneous to the start of tracer injection. A single bolus i.v. injection of 30-50 MBq ${ }^{18}$ F-FDG was injected via the lateral tail vein. Data was then histogrammed with a maximum ring difference of 79 and a span of 3 . Image reconstruction was performed using filtered back projection and ramp filter at 0.5 Nyquist frequency after Fourier rebinning. The attenuation map obtained from the CT scanning was used to correct for photon attenuation with a matrix size of $128 \times$ 128 and a pixel size of $0.796 \mathrm{~mm}$. For image display, interpretation and quantitative analysis, the PET and CT images were loaded onto the Inveon research workplace, a processing software program provided by the system manufacturer [28]. Because of the inline nature of PET/CT scans acquired on this hybrid system, minimal user intervention was needed to co-register the two datasets. The stan- 
dardised uptake value (SUV) was used to quantify the amount of tracer taken up by the region of interest corresponding to the interscapular brown adipose tissue. The equation used to calculate the SUV is as follows:

SUV = average signal intensity $(\mathrm{Mq} / \mathrm{ml}) /$ (injected dose $(\mathrm{MBq}) /$ weight of the animal (g).

Northern Blot Analysis of UCP-1 mRNA Content in Brown Adipose Tissue

The brown adipose tissue located in the interscapular region of the gastric bypass- and shamoperated rats was harvested during necropsy on post-operative day 50, weighed and snap frozen in liquid nitrogen. Samples were stored at $-80{ }^{\circ} \mathrm{C}$ until subsequent measurement of UCP-1 mRNA content by northern Blotting. A cDNA corresponding to nucleotides 368-687 of the mouse UCP-1 (accession\# BC012701) was generated from total brown adipose tissue RNA by RT-PCR with the specific primers 5'-A AGGCCAGGCTTCCAGTACTATTAGG-3' (forward) and 5'- GGTTTGATCCCATGCAGATGGCTCTG-3' (reverse). Northern blot analysis was performed as described previously [29]. The filters were exposed to storage phosphor screens (GE Healthcare Life Sciences, Little Chalfont, UK) and quantified using a Storm imaging system (GE Healthcare Life Sciences). The filter was probed for oligo dT to quantify expression for each tissue sample.

Statistics

All data were normally distributed and are expressed as mean \pm SEM. Unpaired Student's t-test was used to test for significant differences. $P<0.05$ was considered statistically significant.

\section{Results}

\section{Body Weight}

Figure 1A shows the body weight changes for both groups throughout the observation period of 50 days. There was no significant difference in pre-operative body weight between the two groups (day 0: sham $376.2 \pm 7.8 \mathrm{~g}$ vs. gastric bypass $399.8 \pm 12.6 \mathrm{~g} ; \mathrm{p}=0.14$ ). After a short period of post-surgical weight loss, sham-operated controls constantly gained weight for the rest of the study. In contrast, gastric bypass animals lost $25 \%$ of their body weight during the first 30 days after surgery and then plateaued to a final body weight of approximately $300 \mathrm{~g}$. Body weight was significantly lower in gastric bypass rats compared to the sham-operated animals up from day 15 after surgery (sham $375.9 \pm 9.3 \mathrm{~g}$ vs. gastric bypass: $325.3 \pm 13.7 \mathrm{~g} ; \mathrm{p}=0.009$ ). On post-operative day 50, the difference in body weight was 114 $\mathrm{g}$ between the two groups (day 50 : sham $403.8 \pm 8.9 \mathrm{~g}$ vs. gastric bypass $289.0 \pm 13.3 \mathrm{~g}$; $<0.001)$.

\section{Spontaneous Food Intake}

Differences in food intake followed similar patterns as the body weight development. Figure 1B shows the average daily food intake for both groups throughout the complete observation period (day 1 to day 50 after surgery). Average daily food intake was consistently lower after gastric bypass compared to that in sham-operated rats (sham $31.5 \pm 0.35$ g vs. gastric bypass $19.9 \pm 0.58 \mathrm{~g}, \mathrm{p}<0.001)$.

\section{Body Composition}

As shown in figure 2A, gastric bypass rats had a significantly lower percentage of whole body adiposity as determined by ${ }^{1} \mathrm{H}$-MR spectroscopy compared to sham-operated rats (sham $11.1 \pm 1.7 \%$ vs. bypass $3.0 \pm 0.6 \% ; \mathrm{p}=0.001$ ). As shown in figure $2 \mathrm{~B}$, this equated to a significantly lower lean mass of $252.7 \pm 16.5 \mathrm{~g}$ for the bypass rats compared to 346.4 $\pm 6.6 \mathrm{~g}$ for the sham-operated rats $(\mathrm{p}<0.001)$. 


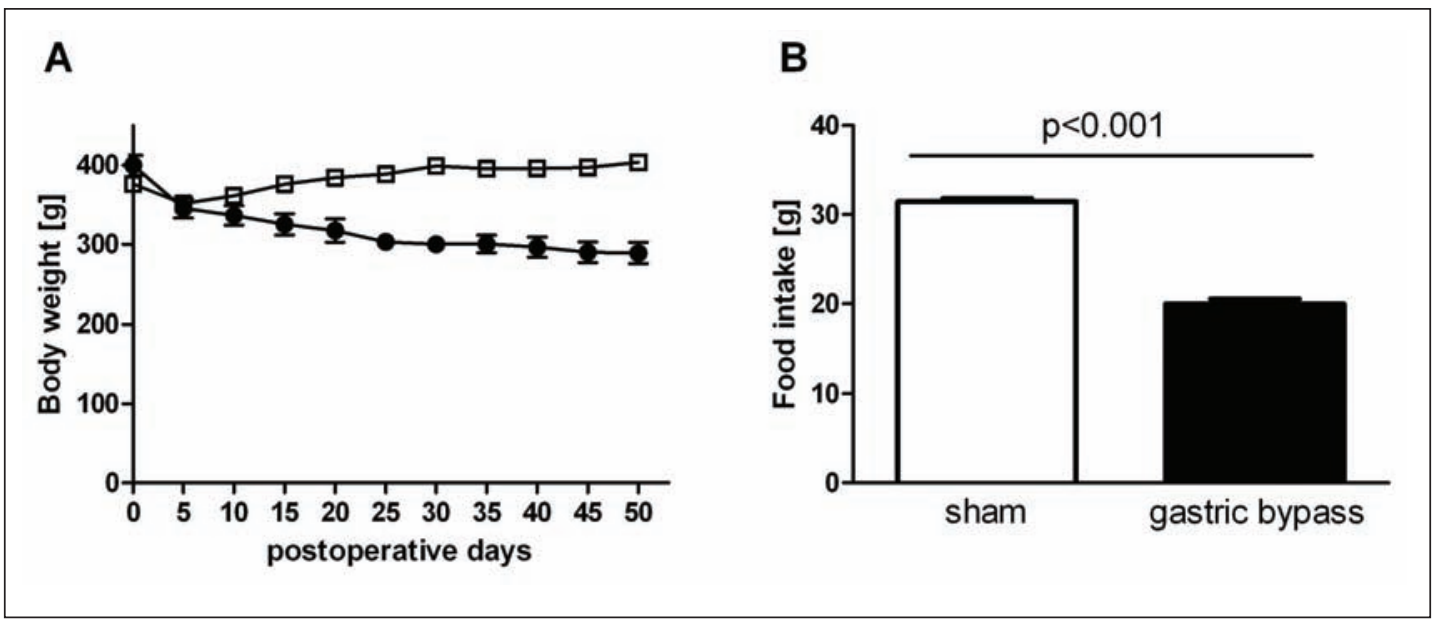

Fig. 1. Body weight change (A) and average daily food intake (B) of sham-operated rats (white, $n=8$ ) and gastric bypass rats (black, $\mathrm{n}=8$ ) throughout the entire observation period of 50 days. Data are shown as mean values $\pm \mathrm{SEM}$.
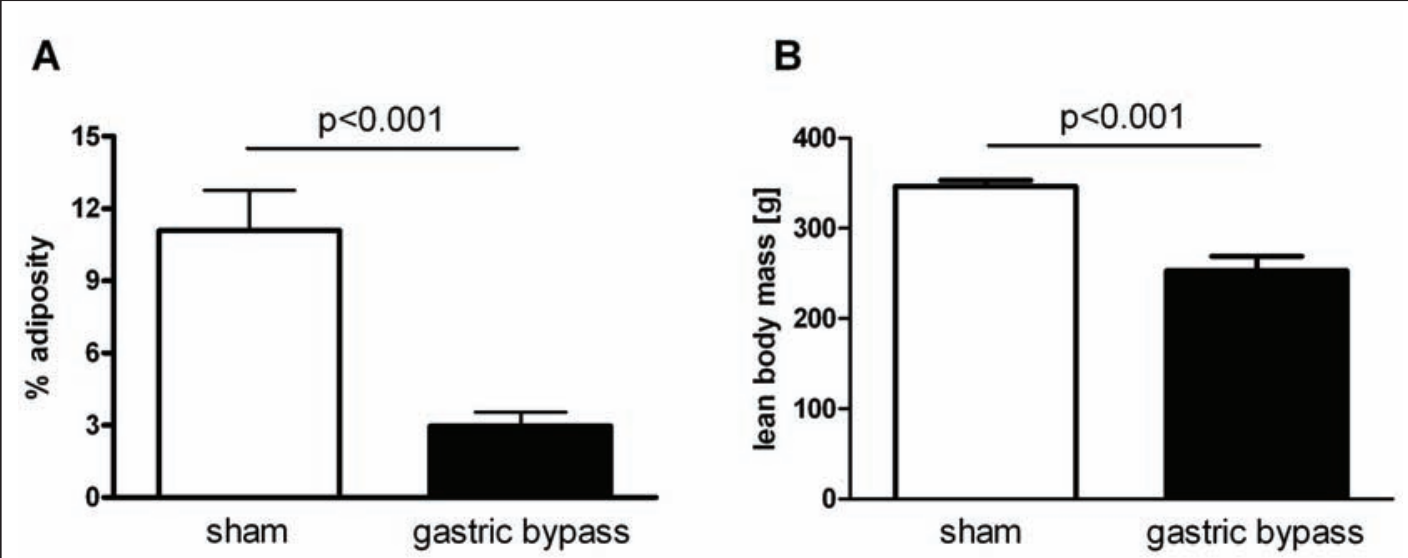

Fig. 2. Percentage whole body adiposity in sham-operated rats (white) and gastric bypass rats (black) using whole body $1 \mathrm{H}-\mathrm{MR}$ spectroscopy on postoperative day 45 . Data are shown as mean \pm SEM.

\section{${ }^{18}$ F-FDG-PET/CT Imaging}

The interscapular brown adipose tissue was easily localised due to the butterfly-shaped nature of the organ (fig. 3). Mean intensity of ${ }^{18}$ F-FDG uptake was taken, and the SUVs [30] for each animal were calculated as described above. Figure 4A shows that sham-operated rats had an SUV of $2.81 \pm 0.58$ and gastric bypass rats had an SUV of $2.56 \pm 0.46$, with no significant difference between the groups $(p=0.73)$. Figure $4 \mathrm{~B}$ shows that, by calculating SUV according to lean mass, a trend towards an increased uptake of ${ }^{18} \mathrm{~F}$-FDG in bypass rats compared to sham-operated rats is observed (SUV in sham-operated rats $3.89 \pm 0.86$ and SUV in gastric bypass rats $4.99 \pm 0.85$ ); however, this did not attain statistical significance $(p=0.39)$. 

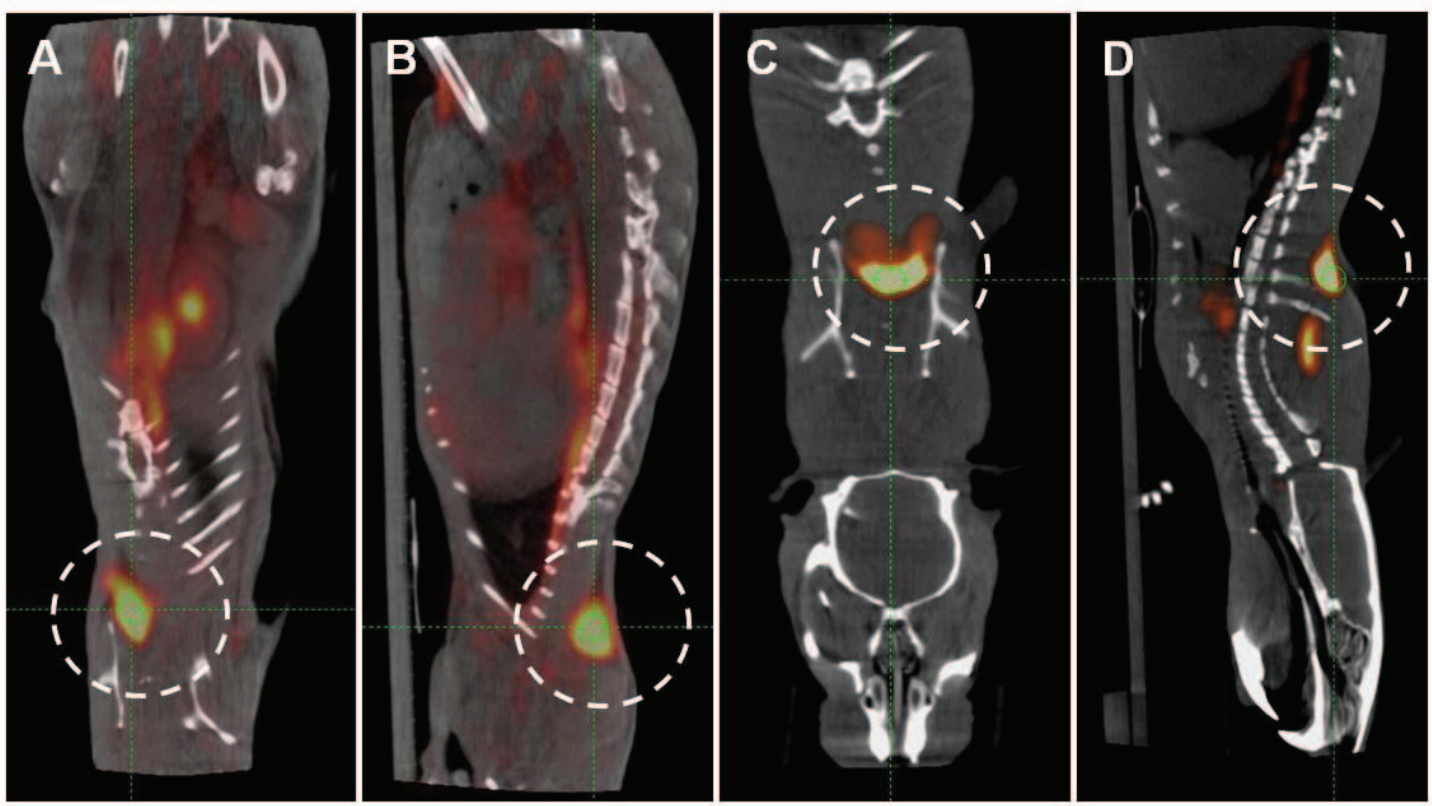

Fig. 3. Fused PET-CT images of rats receiving bolus i.v. injections of $200 \mu \mathrm{l} 30-50 \mathrm{MBq}{ }^{18} \mathrm{~F}-\mathrm{FDG}$ on postoperative day 40. Horizontal (A, C) and sagittal (B, D) images of sham-operated rats (A, B) and gastric bypass rats (C, D) after i.p. administration of $1 \mathrm{mg} / \mathrm{kg}$ CL316243 half an hour before PET-CT scans. The white dashed circle in each image highlights the interscapular brown adipose tissue (top: caudal, bottom: cranial).

\section{UCP-1 mRNA Levels}

The average weight of brown adipose tissue was significantly higher in sham-operated rats in comparison to gastric bypass rats (sham $0.46 \pm 0.02 \mathrm{~g}$ vs. bypass $0.36 \pm 0.02 \mathrm{~g} ; \mathrm{p}=$ $0.007)$. However, there was no difference in brown adipose tissue weight relative to the total body weight between the two groups (sham $0.13 \pm 0.01 \%$ vs. bypass $0.12 \pm 0.01 \%$; $p=$ 0.13). Furthermore, there was no difference in the UCP-1 mRNA content of the brown adipose tissue between the two groups, neither absolutely (fig. 5A, sham $49.5 \pm 13.2$ vs. bypass 43.7 $\pm 13.1 ; \mathrm{p}=0.77$ ) nor in relation to the brown adipose tissue weight (fig. 5B, sham $109.5 \pm$ 32.3 per g brown adipose tissue vs. bypass $128.8 \pm 42.8$ per g brown adipose tissue; $\mathrm{p}=$ $0.72)$.

\section{Discussion}

Since bariatric surgery increases diet-induced thermogenesis in rats [13], a phenomenon potentially mediated by sympathetic nervous system-induced activation of brown adipose tissue [31], we conducted PET/CT experiments with the metabolic tracer ${ }^{18} \mathrm{~F}$-FDG to assess whether brown adipose tissue activity is altered after gastric bypass surgery. Our results reveal that ${ }^{18} \mathrm{~F}$-FDG uptake in brown adipose tissue following appropriate stimulation by an adrenergic receptor agonist is not increased following gastric bypass surgery. Adrenalineinduced thermogenesis and glucose uptake in brown adipose tissue is dependent on the presence of the mitochondrial protein UCP-1 [32]. We found no difference in UCP-1 mRNA expression in brown adipose tissue between gastric bypass rats and sham-operated controls. This suggests that mechanisms other than increased activity of brown adipose tissue are 


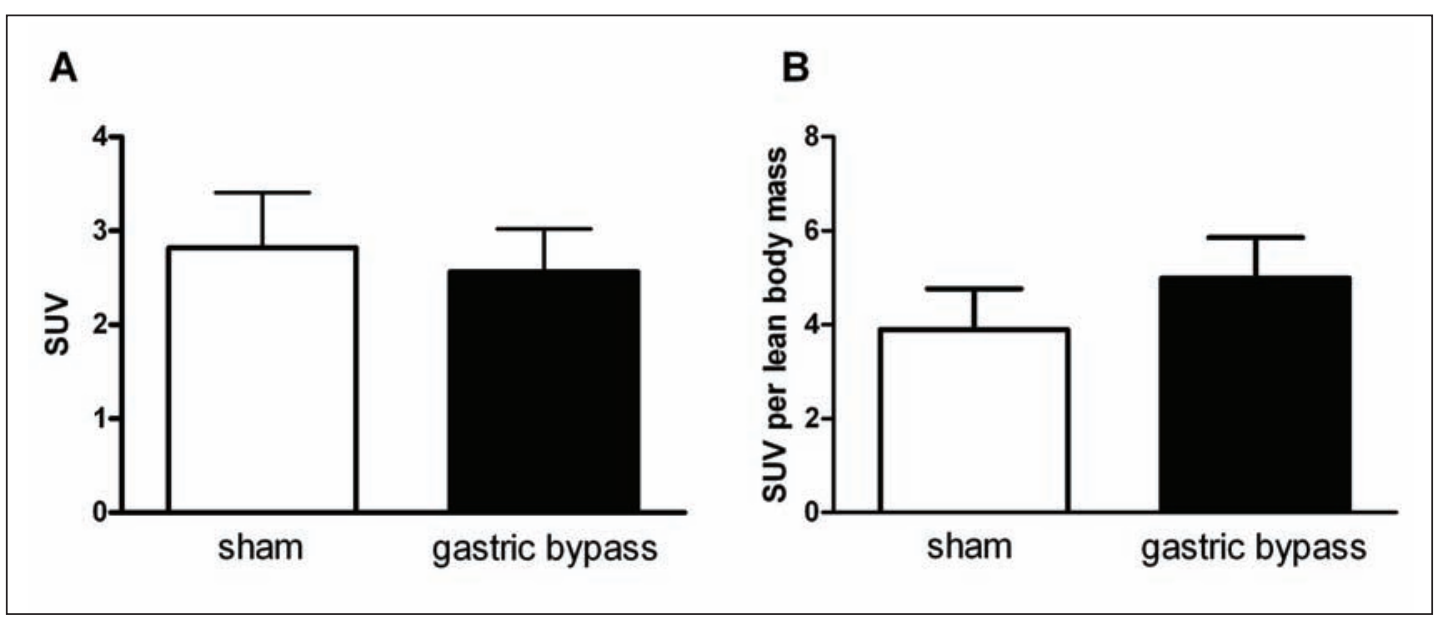

Fig. 4. Standardized uptake values (SUV) relative to $\mathbf{A}$ complete body weight and to $\mathbf{B}$ lean body mass of ${ }^{18}$ F-FDG uptake in the brown adipose tissue of sham-operated (white) and gastric bypass rats (black). Data are shown as mean \pm SEM.

A

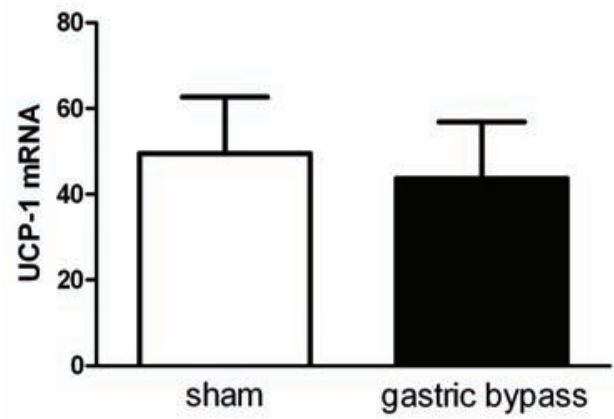

B

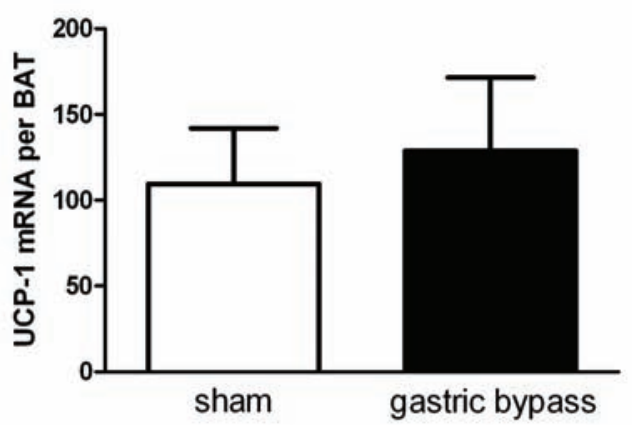

Fig. 5. A Absolute UCP-1 mRNA content and B relative to the brown adipose tissue weight (BAT) of shamoperated (white) and gastric bypass rats (black). Data are shown as mean \pm SEM.

responsible for the higher levels of energy expenditure that have been observed after gastric bypass surgery in rats $[13,14]$. We further confirmed that body weight loss after gastric bypass was associated with a higher percentage adipose tissue mass loss compared to lean body mass loss [13].

Our findings are in line with previous reports demonstrating an increased oxygen consumption following feeding in rats which was not accounted for by increased oxygen consumption by interscapular brown adipose tissue [33]. Therefore, other tissues like skeletal muscles or liver being sensitive to adrenergic stimulation may be responsible for the diet-induced increase in oxygen uptake or diet-induced thermogenesis [34], thus further questioning the role of brown adipose tissue in rats [34]. In contrast, brown adipose tissue 
Hankir et al.: Increased Energy Expenditure in Gastric Bypass Rats Is Not Caused by Activated Brown Adipose Tissue

in mice seems to play an important role in diet-induced thermogenesis. Observations that strongly support a species difference between rats and mice come from PET/CT experiments that demonstrated a significantly increased uptake of ${ }^{18} \mathrm{~F}-\mathrm{FDG}$ in interscapular brown fat of fed versus fasted mice [35]. In line with this, we also failed to find an increased ${ }^{18} \mathrm{~F}$-FDG uptake in brown adipose tissue after consumption of a 5-gram meal following a 12-hour fast in gastric bypass rats when compared to sham-operated controls (data not shown). Furthermore, knockout of the brown adipose tissue-specific protein UCP-1 in mice results in a loss of diet-induced thermogenesis [24].

We and others have previously demonstrated that gastric bypass rats have a higher total energy expenditure when compared to ad libitum fed and body weight-matched sham controls $[13,14]$. The increased energy expenditure did not correlate with differences in activity and/or body temperature, and other processes such as mal-absorption and inflammation were excluded $[13,14]$. It was shown that the differences were mainly due to changes in the maintenance energy expenditure during the light phase when physical activity is typically low [13]. As gastric bypass rats showed a greater cumulative increase in total energy expenditure after a 5-gram test meal than the control groups, we suggested that dietinduced thermogenesis may play a role [13]. Gastric bypass significantly rearranges the gastrointestinal anatomy, and alterations in gastrointestinal and central neuroendocrine signal circuits may partly be responsible for the increased energy expenditure after gastric bypass $[13,14]$.

In line with previous studies, the present study confirms that gastric bypass surgery is an effective means to reduce body weight and maintain body weight loss [8]. Gut hormones may contribute to the reduced daily food intake $[8,36,37]$. Another potential mechanism is an adjusted leptin 'set point' where the plasma leptin which is perceived by the hypothalamus as a state of energy insufficiency is reduced [38]. Thus compensatory mechanisms during the weight-reduced state such as increased food intake and/or decreased energy expenditure remain absent. Mechanisms which determine the leptin set point are unknown, but possible mechanisms include increased leptin receptor expression in the rat hypothalamus after gastric bypass [39] or a higher affinity of leptin to these receptors [38]. Alternatively, the balance triggering the 'starvation response' opposing weight loss triggered by lower leptin levels is altered by increased levels of circulating anorexigenic gut hormones such as PYY and GLP-1 [8].

Our study was limited to activation of brown adipose tissue by a $\beta-3$ adrenergic receptor agonist which is a satisfactory means to test for diet-induced thermogenesis [24]. Stimulation by cold temperatures which engages sensory primary afferent fibres and neurons in the anterior hypothalamus to stimulate the sympathetic nervous system [40] still needs to be performed to confirm that temperature-induced thermogenesis does not change post bypass surgery in rats.

Additionally, diet-induced thermogenesis in rodents has traditionally been tested for following consumption of a high-fat diet [24, 31]. Nevertheless, diet-induced thermogenesis is still observed when placing animals on a normal chow diet [13]. It would be interesting to test if placing gastric bypass rats on a high-fat diet would further exacerbate differences in diet-induced thermogenesis compared to sham-operated controls and whether this would be a brown adipose tissue-mediated phenomenon.

In conclusion, gastric bypass does not appear to increase the activity of brown adipose tissue in rats. Further studies are required to investigate the physiological mechanisms mediating increased energy expenditure after gastric bypass with the ultimate goal to develop safer surgical or non-surgical alternatives to treat morbid obesity. Our results cannot be used to justify the radiation dose of ${ }^{18} \mathrm{~F}$-FDG PET/CT studies in humans to determine potential changes in brown adipose tissue after gastric bypass surgery. 
Hankir et al.: Increased Energy Expenditure in Gastric Bypass Rats Is Not Caused by Activated Brown Adipose Tissue

\section{Acknowledgement}

The financial support by the Deutsche Forschungsgemeinschaft (BU 2430/1-1 and 1-2) (M.B. and F.S.) and the Medical Research Council (MRC) is gratefully acknowledged. S.B. and C.le R. were supported by a Department of Health Clinician scientist award. KLS is supported by a BBSRC New Investigator Award. Imperial College London receives support from the NIHR Biomedical Research Centre funding scheme.

\section{Disclosure Statement}

The authors declare no competing financial interests in relation to the work described in this manuscript.

\section{References}

Visscher TL, Seidell JC: The public health impact of obesity. Annu Rev Public Health 2001;22:355-375.

Allison DB, Saunders SE: Obesity in North America. An overview. Med Clin North Am 2000;84:305-332, v. Hedley AA, Ogden CL, Johnson CL, Carroll MD, Curtin LR, Flegal KM: Prevalence of overweight and obesity among US children, adolescents, and adults, 1999-2002. JAMA 2004;291:2847-2850.

4 Adams TD, Gress RE, Smith SC, Halverson RC, Simper SC, Rosamond WD, Lamonte MJ, Stroup AM, Hunt SC: Long-term mortality after gastric by pass surgery. N Engl J Med 2007;357:753-761.

5 Sjostrom L, Narbro K, Sjostrom CD, Karason K, Larsson B, Wedel H, Lystig T, Sullivan M, Bouchard C, Carlsson B, Bengtsson C, Dahlgren S, Gummess on A, Jacobson P, Karlsson J, Lindroos AK, Lonroth H, Naslund I, Olbers T, Stenlof K, Torgerson J, Agren G, Carlsson LM: Effects of bariatric surgery on mortality in Swedish obese subjects. N Engl J Med 2007;357:741-752.

- 6 Buchwald H, Oien DM: Metabolic/bariatric surgery worldwide 2008. Obes Surg 2009;19:1605-1611.

7 Greenway FL: Surgery for obesity. Endocrinol Metab Clin North Am 1996;25:1005-1027.

- 8 le Roux CW, Aylwin SJ, Batterham RL, Borg CM, Coyle F, Prasad V, Shurey S, Ghatei MA, Patel AG, Bloom SR: Gut hormone profiles following bariatric surgery favor an anorectic state, facilitate weight loss, and improve metabolic parameters. Ann Surg 2006;243:108-114.

- 9 le Roux CW, Welbourn R, Werling M, Osborne A, Kokkinos A, Laurenius A, Lonroth H, Fandriks L, Ghatei MA, Bloom SR, Olbers T: Gut hormones as mediators of appetite and weight loss after Roux-en-Y gastric bypass. Ann Surg 2007;246:780-785.

10 Burge JC, Schaumburg JZ, Choban PS, DiSilvestro RA, Flancbaum L: Changes in patients' taste acuity after Roux-en-Y gastric bypass for clinically severe obesity. J Am Diet Assoc 1995;95:666-670.

-11 Scruggs DM, Buffington C, Cowan GS Jr: Taste acuity of the morbidly obese before and after gastric bypass surgery. Obes Surg 1994;4:24-28.

12 Olbers T, Bjorkman S, Lindroos A, Maleckas A, Lonn L, Sjostrom L, Lonroth H: Body composition, dietary intake, and energy expenditure after laparoscopic Roux-en-Y gastric bypass and laparoscopic vertical banded gastroplasty: a randomized clinical trial. Ann Surg 2006;244:715-722.

13 Bueter M, Lowenstein C, Olbers T, Wang M, Cluny NL, Bloom SR, Sharkey KA, Lutz TA, le Roux CW: Gastric bypass increases energy expenditure in rats. Gastroenterology 2010;138:1845-1853.

14 Stylopoulos N, Hoppin AG, Kaplan LM: Roux-en-Y gastric bypass enhances energy expenditure and extends lifespan in diet-induced obese rats. Obesity (Silver Spring) 2009;17:1839-1847.

-15 Lowell BB, Spiegelman BM: Towards a molecular understanding of adaptive thermogenesis. Nature 2000; 404:652-660.

16 Nedergaard J, Golozoubova V, Matthias A, Shabalina I, Ohba K, Ohlson K, Jacobsson A, Cannon B: Life without UCP1:mitochondrial, cellular and organismal characteristics of the UCP1-ablated mice. Biochem Soc Trans 2001;29:756-763.

17 Cypess AM, Lehman S, Williams G, Tal I, Rodman D, Goldfine AB, Kuo FC, Palmer EL, Tseng YH, Doria A, Kolodny GM, Kahn CR: Identification and importance of brown adipose tissue in adult humans. N Engl J Med 2009;360:1509-1517.

18 van Marken Lichtenbelt WD, Vanhommerig JW, Smulders NM, Drossaerts JM, Kemerink GJ, Bouvy ND, Schrauwen P, Teule GJ: Cold-activated brown adipose tissue in healthy men. N Engl J Med 2009;360:15001508.

19 Virtanen KA, Lidell ME, Orava J, Heglind M, Westergren R, Niemi T, Taittonen M, Laine J, Savisto NJ, Enerback S, Nuutila P: Functional brown adipose tissue in healthy adults. N Engl J Med 2009;360:1518-1525.

-20 Tseng YH, Kokkotou E, Schulz TJ, Huang TL, Winnay JN, Taniguchi CM, Tran TT, Suzuki R, Espinoza DO, Yamamoto Y, Ahrens MJ, Dudley AT, Norris AW, Kulkarni RN, Kahn CR: New role of bone morphogenetic protein 7 in brown adipogenesis and energy expenditure. Nature 2008;454:1000-1004. 
Hankir et al.: Increased Energy Expenditure in Gastric Bypass Rats Is Not Caused by Activated Brown Adipose Tissue drial uncoupling protein are cold-sensitive but not obese. Nature 1997;387:90-94.

Feldmann HM, Golozoubova V, Cannon B, Nedergaard J: UCP1 ablation induces obesity and abolishes dietinduced thermogenesis in mice exempt from thermal stress by living at thermoneutrality. Cell Metab 2009; 9:203-209.

25 Bueter M, Lowenstein C, Ashrafian H, Hillebrand J, Bloom SR, Olbers T, Lutz T, le Roux CW: Vagal sparing surgical technique but not stoma size affects body weight loss in rodent model of gastric bypass. Obes Surg 2010;20:616-622.

26 So PW, Herlihy AH, Bell JD: Adiposity induced by adenovirus 5 inoculation. Int J Obes (Lond) 2005;29:603606.

27 Visser EP, Disselhorst JA, Brom M, Laverman P, Gotthardt M, Oyen WJ, Boerman OC: Spatial resolution and sensitivity of the Inveon small-animal PET scanner. J Nucl Med 2009;50:139-147.

-28 Bao Q, Newport D, Chen M, Stout DB, Chatziioannou AF: Performance evaluation of the inveon dedicated PET preclinical tomograph based on the NEMA NU-4 standards. J Nucl Med 2009;50:401-408.

29 Taheri S, Gardiner J, Hafizi S, Murphy K, Dakin C, Seal L, Small C, Ghatei M, Bloom S: Orexin A immunoreactivity and preproorexin mRNA in the brain of Zucker and WKY rats. Neuroreport 2001;12:459-464.

-30 Thie JA: Understanding the standardized uptake value, its methods, and implications for usage. J Nucl Med 2004;45:1431-1434.

-31 Rothwell NJ, Stock MJ: A role for brown adipose tissue in diet-induced thermogenesis. Obes Res 1997;5: 650-656.

-32 Inokuma K, Ogura-Okamatsu Y, Toda C, Kimura K, Yamashita H, Saito M: Uncoupling protein 1 is necessary for norepinephrine-induced glucose utilization in brown adipose tissue. Diabetes 2005;54:1385-1391.

33 Ma SW, Foster DO, Nadeau BE, Triandafillou J: Absence of increased oxygen consumption in brown adipose tissue of rats exhibiting 'cafeteria' diet-induced thermogenesis. Can J Physiol Pharmacol 1988;66:13471354.

-34 Kozak LP: Brown fat and the myth of diet-induced thermogenesis. Cell Metab 2010;11:263-267.

-35 Fueger BJ, Czernin J, Hildebrandt I, Tran C, Halpern BS, Stout D, Phelps ME, Weber WA: Impact of animal handling on the results of 18F-FDG PET studies in mice. J Nucl Med 2006;47:999-1006.

-36 Korner J, Bessler M, Cirilo LJ, Conwell IM, Daud A, Restuccia NL, Wardlaw SL: Effects of Roux-en-Y gastric bypass surgery on fasting and postprandial concentrations of plasma ghrelin, peptide YY, and insulin. J Clin Endocrinol Metab 2005;90:359-365.

37 Shin AC, Zheng H, Townsend RL, Sigalet DL, Berthoud HR: Meal-induced hormone responses in a rat model of Roux-en-Y gastric bypass surgery. Endocrinology 2010;151:1588-1597.

38 Flier JS: Clinical review 94: what's in a name? In search of leptin's physiologic role. J Clin Endocrinol Metab 1998;83:1407-1413.

39 Guijarro A, Suzuki S, Chen C, Kirchner H, Middleton FA, Nadtochiy S, Brookes PS, Niijima A, Inui A, Meguid MM: Characterization of weight loss and weight regain mechanisms after Roux-en-Y gastric bypass in rats. Am J Physiol Regul Integr Comp Physiol 2007;293:R1474-R1489.

40 Hammel HT, Hardy JD, Fusco MM: Thermoregulatory responses to hypothalamic cooling in unanesthetized dogs. Am J Physiol 1960;198:481-486. 